\title{
Condition for Good Quality of Life after Surgery for Slow Transit Constipation
}

\author{
Yong Hee Hwang \\ Department of Surgery, Sahmyook Medical Center, Seoul, Korea
}

\section{See Article on Page 180-187}

We were able to identify subgroups of patients by using physiologic tests that accurately predicted those who would respond well to surgery [1]. Only those patients documented, by using a marker transit study or by using scintigraphic transit, as having slow-transit constipation were deemed to be candidates for surgery, and the success rate of a colectomy for colonic inertia was significantly higher in patients who underwent a repeat transit study confirming inertia than in patients who underwent a colectomy based on a single study. Thus, consideration should be given to repeating the colonic transit study before a colectomy to help secure the diagnosis and to improve the outcome [2].

Surgeons have performed a total abdominal colectomy with ileorectal anastomosis and a subtotal colectomy with ileosigmoid or cecorectal anastomosis for colonic inertia. A cecorectal anastomosis, while preserving the ileocecal valve with the theoretical advantage of water preservation, is often complicated by cecal distention. Sigmoid preservation also predisposes patients to postoperative constipation. Today, a total abdominal colectomy remains the treatment of choice for colonic inertia. However, despite its excellent success rate, postoperative morbidity remains a discouraging problem. The incidence of abdominal pain and bloating are less likely to subside after a colectomy perhaps because of irritable bowel syndrome [3]. A long-term follow-up study reported a slight decrease in bowel frequency, a change in stool consistency (semi-liquid to semisolid), and a decreased incidence of fecal incontinence, possibly because of small-bowel adaptation [4]. In summary, I agree

Correspondence to: Yong Hee Hwang, M.D.

Department of Sugery, Sahmyook Medical Center, 29-1 Hwigyeong 2-dong, Dongdaemun-gu, Seoul 130-711, Korea

Tel: +82-2-2210-3563, Fax: +82-2-2212-2673

E-mail: hwangyon@hotmail.com

(C) 2011 The Korean Society of Coloproctology

This is an open-access article distributed under the terms of the Creative Commons Attribution NonCommercial License (http://creativecommons.org/licenses/by-nc/3.0) which permits unrestricted noncommercial use, distribution, and reproduction in any medium, provided the original work is properly cited. with the author's opinion, and I think a total abdominal colectomy can be recommended to patients with well-established colonic inertia.

\section{REFERENCES}

1. Pemberton JH, Rath DM, Ilstrup DM. Evaluation and surgical treatment of severe chronic constipation. Ann Surg 1991;214:403-11.

2. Nam YS, Pikarsky AJ, Wexner SD, Singh JJ, Weiss EG, Nogueras $\mathrm{JJ}$, et al. Reproducibility of colonic transit study in patients with chronic constipation. Dis Colon Rectum 2001;44:86-92.

3. Kamm MA, Hawley PR, Lennard-Jones JE. Outcome of colectomy for severe idiopathic constipation. Gut 1988;29:969-73.

4. Pikarsky AJ, Singh JJ, Weiss EG, Nogueras JJ, Wexner SD. Longterm follow-up of patients undergoing colectomy for colonic inertia. Dis Colon Rectum 2001;44:179-83. 